IZA DP No. 10292

Technical Efficiency, Unions and

Decentralized Labor Contracts

Francesco Devicienti

Alessandro Manello

Davide Vannoni

October 2016 


\title{
Technical Efficiency, Unions and Decentralized Labor Contracts
}

\author{
Francesco Devicienti \\ University of Turin, \\ Collegio Carlo Alberto and IZA \\ Alessandro Manello \\ University of Turin \\ and IRCrES-CNR \\ Davide Vannoni \\ University of Turin, \\ Collegio Carlo Alberto and IRCrES-CNR
}

\section{Discussion Paper No. 10292 \\ October 2016}

\author{
IZA \\ P.O. Box 7240 \\ 53072 Bonn \\ Germany \\ Phone: +49-228-3894-0 \\ Fax: +49-228-3894-180 \\ E-mail: iza@iza.org
}

\begin{abstract}
Any opinions expressed here are those of the author(s) and not those of IZA. Research published in this series may include views on policy, but the institute itself takes no institutional policy positions. The IZA research network is committed to the IZA Guiding Principles of Research Integrity.

The Institute for the Study of Labor (IZA) in Bonn is a local and virtual international research center and a place of communication between science, politics and business. IZA is an independent nonprofit organization supported by Deutsche Post Foundation. The center is associated with the University of Bonn and offers a stimulating research environment through its international network, workshops and conferences, data service, project support, research visits and doctoral program. IZA engages in (i) original and internationally competitive research in all fields of labor economics, (ii) development of policy concepts, and (iii) dissemination of research results and concepts to the interested public.
\end{abstract}

IZA Discussion Papers often represent preliminary work and are circulated to encourage discussion. Citation of such a paper should account for its provisional character. A revised version may be available directly from the author. 


\section{ABSTRACT}

\section{Technical Efficiency, Unions and Decentralized Labor Contracts}

This paper explores the link between the presence of unions in the workplace, the adoption of decentralized labor agreements and technical efficiency, using a large sample of Italian manufacturing firms. We apply the Data Envelopment Analysis, and its robust version based on bootstrap theory, to get reliable estimates of technical efficiency at the firm level in a standard first stage. We devote particular attention to the specific technology adopted, by distinguishing 20 different sector frontiers, as well as to the presence of outliers. The obtained efficiency scores are analyzed in a second stage applying a truncated regression model estimated via Maximum Likelihood, following the Simar and Wilson $(2007,2011)$ methodology. Our results highlight that the presence of workplace unionization decreases the level of technical efficiency, while aspects limiting the unions' power such as a strong exposure to international markets, high debt levels or the prevalence of flexible assets partially reduce the negative effect. However, when firms adopt decentralized labor contracts agreements, the effect on efficiency is positive and partially compensates the negative unions' effect. The results are robust to the inclusion of many firm characteristics and to different model specifications.

JEL Classification: J51, D22, D24, C24, C44

Keywords: technical efficiency, trade unions, decentralized bargaining, data envelopment analysis, truncated regression model

Corresponding author:

Alessandro Manello

Department of Economics, Mathematics and Statistics

University of Turin

Corso Unione Sovietica 218 bis

Turin

Italy

E-mail: alessandro.manello@unito.it 


\section{Introduction}

The ongoing debate on the Italian productivity crisis, in particular for the manufacturing industry, has been recently revived by a deep discussion on the alleged beneficial consequences of labor market reforms and the role of unions. In particular, the effect of unions on firm's productivity is one of the current hottest topic in Italy, with an increasing attention devoted by media, fostered by the delicate discussion, at the institutional level, on the future role of unions. If, on the one hand, the business community, members of the government and policy commentators often include unions among the factors behind the Italian productivity crisis, employees and trade unionists, on the other hand, highlight their fundamental role to protect workers' rights and to promote cooperation and communication.

The debate on these aspects is not new, but the numerous contributions still fail to reach an empirical consensus on the real effects of unions on firm productivity, in line with the theory that identifies the so called two faces of unionism (Freeman and Medoff, 1984): the monopoly face and the collective voice/institutional response face $(\mathrm{CV} / \mathrm{IR})$. The monopoly face synthesizes the different adverse effects for the firm, based or not on wage aspects. To begin with, unions can engage in rent-seeking activities, raising labor costs and reducing firms' profitability. As discussed in the hold-up literature, unions' opportunistic behavior may translate into a tax on a firm's capital investment and be detrimental to its innovation activities (see Card et al., 2014, and Cardullo et al., 2015, for recent contributions on the hold-up problem in OECD countries). Moreover, the unions can take different actions that limit workplace flexibility, encourage restrictive work rules or weaken employees' efforts (Kaufman, 2004). As a consequence, firms appear less flexible and adaptable to environmental shocks, and this impacts negatively on productivity. For instance, the presence of unions may limit a store's opening hours and reduce its competitive advantage with respect to non-unionized stores, which are therefore better able to adapt to new market trends. On the contrary, the CV/IR face highlights how the presence of unions increases the communication channels between the workforce and the management, reinforcing the voice option for employees ${ }^{1}$. The outcome is a reduction of dissatisfaction at the workplace, absenteeism and turnover, with a general positive effect on productivity. In particular, the containment of excess worker turnover reduces human capital dispersion and training costs, and avoids the costly expression of the exit option by the employees (Ton and Huckman, 2008).

If unions can be considered as promoters and main actors of the voice option, the adoption of decentralized labor contract agreements (DLCAs), which integrate or derogate the national and industry-wide collective agreements, may represent the effective means of voice and imply a smoother conflict among employees and entrepreneurs. A general tendency towards the decentralization of labor contract bargaining has been

\footnotetext{
${ }^{1}$ The exit-voice dichotomy has been introduced by Hirschman (1970) and represents two sides of social interactions: the voice option suggests how it is possible to discuss and to contribute to a better environment, while the exit option represents a more radical choice of not discussing and exiting the relationship.
} 
recently suggested by the European Council $^{2}$, for its potential positive effects on productivity. The latter should stem from a better mix of wage settlements and more flexible terms in the organization of labor, which should be able to increase the satisfaction of the employees, their effort and firm attachment, reduce turnover, as well as improve firm's adaptability to changing market conditions.

Although there is a widespread interest on the potential effects of increasing decentralized bargaining, the recent scientific literature remains mainly focused on the influence of Performance Related Pay (PRP) schemes, one of the main components of firm local agreements, and investigates in particular their effect on productivity at the individual level (Bandiera et al., 2005). However, the flexibility of wages, still limited in magnitude, is manly accepted and adopted in a collective form, with a modest expected effect on productivity (e.g., Lucifora and Origo, 2015; Gielen et al. 2010). In the Italian context, the majority of firms adopting a decentralized contract also introduce a PRP scheme, typically on a collective basis, with a potentially limited effect on the employees' efforts. However, DLCAs can also sustain productivity through other channels not directly linked to wages, like additional flexibility in working hours and labor organization, and other clauses that increase trust and cooperation among employees and managers. The recent case of FIAT (now FCA) that decided to exit Confindustria (the main association representing manufacturing and service companies) and consequently to leave behind the National Labor Contract Agreements (NCLA) in order to apply more flexible (and mainly not wage-based) terms, represents a valid example of the issue. Moreover, DLCAs are the direct instrument through which unions make the voice option effective: they contribute to create a better working environment, to increase the employees' commitment with the firm and to favor a cooperative approach with the firms' managers. On top of these aspects, a DLCA can also be considered as an instrument to limit the monopoly face of unions and its opportunistic behavior, in that it formally specifies wage and non-wage claims through a written contract over a relatively long period of time (usually 3 years, and sometimes more). When the firm and the unions jointly discuss and bargain over wages and numerous other aspects of the employment relation or the organization of labor - as is often the case for the DLCAs observed in practice - inefficiencies are more likely to be avoided, compared to the outcomes obtained under a traditional monopoly union setting (e.g., Bennett and Kaufman, 2007). In this respect, the presence of a decentralized contract has a double face: on the one hand, it signals that the voice option has been formally expressed, reducing conflicts and increasing cooperation between the counterparts; on the other hand, it commits the union to a predetermined set of contractual terms (e.g., profit-sharing rules), thereby reducing uncertainty and the union's ex-post opportunistic behavior.

In this paper, we propose to revisit a traditional labor and industrial economics issue using efficiency analysis, a methodology relatively new in these fields. In particular, we compute firms' inefficiency using a Data Envelopment Analysis (DEA) framework, which measures the capacity of obtaining output for any

\footnotetext{
${ }^{2}$ See for example the recent Country-specific recommendations 2015 (Council recommendation, 14 July 2015; 2015/C $272 / 16)$.
} 
given input bundle with respect to the reference frontier. The bulk of previous literature, better analyzed in the next section, is mainly focused on labor productivity and estimates the effect of unions or performance related pay on measures such as value added per employee or revenues per employees ${ }^{3}$. If the impact of unionization and industrial relations can be straightforward on output obtained per unit of labor, their relationship with the technical efficiency level, which considers a complete input bundle, is more interesting. In fact, efficiency score are computed more coherently with the technology, assuming a production function characterized by many inputs combined to obtain outputs. The main advantage of the DEA approach is that the shape of this function, which is unknown, is not imposed, but is derived by the observed input and output bundles through linear programming techniques.

Using a large sample of Italian manufacturing firms observed over the years 2010-2012, we study the impact of both unions and decentralized labor agreements on technical efficiency. From a methodological point of view, we use a semi-parametric approach, which minimizes misspecification issues in the technology definition and compensates the limits of purely deterministic models (see Daraio and Simar, 2007 for a thorough reference). Our results show a clear negative effect of workplace unionization on technical efficiency that remains stable across all estimates; however, such a negative impact is roughly counterbalanced by a positive effect related to the presence of decentralized labor contracts. The obtained results are robust to the introduction of additional controls, as well as to the adoption of a propensity score based method, which is aimed at reducing endogeneity concerns between technical efficiency and unions or decentralized contracts. This paper represents one of the first attempts to combine DEA, truncated regression and propensity score based methods. We also show that the corporate strategies pursued by managers to limit the unions' bargaining power substantially affect the overall negative effect on efficiency. In fact, for firms characterized by higher exposure to international markets, higher debt and more flexible assets (all factors limiting the unions' power) the impact of unions is, on average, lower.

The remainder of the paper is organized as follows. Section 2 reviews the relevant literature on the role of unions and decentralized bargaining. Section 3 describes the DEA model, the bias correction procedure and the second stage analysis. Section 4 presents the database and section 5 illustrates our main results. Some general considerations and policy implications conclude our work.

\section{Literature review and background}

The literature on the effect of unions on productivity, vast and mainly dated, identifies two theoretical mechanisms, one leading to an increase of productivity and the other to a productivity drop (Metcalf, 2003). On the one hand, unions can promote cooperation, monitoring and information sharing between

\footnotetext{
${ }^{3}$ Papers focusing on standard total factor productivity (TFP) represent an exception, too. See Morikawa (2010) for a recent example.
} 
the employees and the management, all factors acting as a stimulus for increasing effort and motivation and contributing to a better workplace environment. On the other hand, they can lead to restrictive work practices, adverse industrial relations, conflicts and rent seeking, factors that contribute to deteriorate trust and cooperation between the employees and the managers, and to reduce investment (hold-up problem) and productivity levels. Despite the wide empirical literature on the relationship between unions and firms' economic performance, a general consensus on the negative impact of unions has been partially reached only as far as profits are concerned ${ }^{4}$, while the effect of unions on productivity remains substantially uncertain. Many surveys on this topic (see, for example, Doucouliagos and Laroche, 2003; Kuhn, 1998; Wilson, 1995; Addison and Hirsch, 1989), which mainly collect evidence from the US, fail in finding a common direction on the effect of unions on productivity. The results of the estimates are generally not stable and strongly influenced by the specificity of the sample, by the industrial sectors considered and by the definition of productivity used. ${ }^{5}$

In continental Europe, the recent literature mainly analyzes the effect of work councils, workplace representative bodies characterized by co-determination and bargaining power at the plant level, rather than the generic effect of unionism. Analyzing German firms, Schedlitzki (2002) finds that work councils have a positive, albeit poorly significant, effect on labor productivity. Positive effects are also reported by Muller (2012 and 2015) and Hübler and Jirjahn (2003), who noticed that the impact is more pronounced in German firms not covered by sectoral collective agreements. On the contrary, Fairris and Askenazy (2010), using a sample of French firms, find a negligible impact on labor productivity from the presence of work councils.

Results are mixed also for the rare works that focus on technical efficiency, rather than labor productivity. Schank et al. (2004) estimate technical efficiency via stochastic frontier analysis for a sample of German firms operating in 1993-1996, finding no significant difference between the median efficiency of firms having a work council and their counterparts without it. Chintrakarn and Chen (2010) estimate a parametric production frontier too, but at the aggregate level, using information on manufacturing sectors in US states. They find mixed results for the presence of unions, in that they are shown to increase efficiency, but to reduce technical progress. The most relevant paper in the field of non-parametric technical efficiency analysis is Greer (2009), who focuses on the air transportation sector. After estimating efficiency via DEA, he runs a Tobit regression to analyze the determinants of technical efficiency. While his findings suggest that union density does not affect technical efficiency, the use of a very specific data-set on US airlines, as well as new methodological developments, leave space for further investigations. Doucouliagos and Laroche (2006) propose another application of DEA in the labor field, investigating the effect of human resource practices on technical efficiency in a sample of French firms. Among other control variables, they include a union

\footnotetext{
${ }^{4}$ See, for some recent reviews, Doucouliagos and Laroche, 2009 and Bennet and Kaufman, 2007.

${ }^{5}$ Contradicting results are also reported in the non-US based literature. For example, Morikawa (2010) analyzes a panel of Japanese firms, finding a $18 \%$ labor productivity premium and a $13 \%$ TFP premium for unionized firms. However, Pencavel (2002) finds for the UK that the impact of unions on productivity is negligible.
} 
dummy in a Tobit regression model aimed at explaining efficiency scores, and find a strong negative effect for unionized firms, which appear to be approximately $13 \%$ less efficient than non-unionized ones.

The effect of decentralized bargaining on productivity and other economic outcomes has been treated only marginally in the literature, with the exception of the German experience of pacts, plant-level agreements characterized by concessions from both bargaining partners, employees and firms, that integrate or partially derogate the collective sectoral agreements. The number of contributions is increasing, but the interest is limited to investigating whether firms adopting the pacts differ in terms of labor productivity and investments in physical capital. Bellmann et al. (2015) find an insignificant effect of pacts on investments using firm level data in the period 2001-2010. On the contrary, Addison et al. (2015) find a consistent and robust effect $(+20 \%)$ on labor productivity for firms adopting pacts, using a wide sample of German firms operating in 19 sectors, in the period 2006-2009.

Regarding the empirical evidence from Italy, the most recent and relevant works focus on Flexible Pay Systems (FPS) such as Performance Related Pay (PRP), often foreseen by decentralized bargaining in order to gain wage flexibility ${ }^{6}$. Origo (2009), analyzing a panel of firms operating in the metalworking sector in the years 1989-1997, finds a positive effect of FPS on labor productivity (7-11\%) using diff-in-diff estimators to account for endogenity issues, which seems to be larger for highly unionized firms. Antonietti et al. (2014) investigate the adoption of FPS, and find a positive effect on labor productivity, during the years 2009-2011. The authors use a sample of firms located in an Italian region (Emilia Romagna) and control for endogeneity through a two-stage procedure ${ }^{7}$. Damiani et al. (2016) analyze the direct link between PRP and labor productivity by applying a quantile regression (and its IV extension) on survey data ${ }^{8}$ from manufacturing firms in the period 2005-2007-2010, finding a positive effect on labor productivity (9.5\%) that is substantially uniform and significant across all the quantiles. ${ }^{9}$ Lucifora and Origo (2015), working on a sample of 3000 Italian firms operating in the metal engineering sector during the period 1989-1999, find a positive, but rather limited effect (3-5\%) of PRP on labor productivity.

Our paper complements this existing research in two main respects. First, we focus more generally on technical efficiency, rather than on labor productivity. Second, we aim at explicitly separating the productivity impact of workplace unionization per se, from the effect of having formally signed a decentralized labor contract agreements.

\footnotetext{
${ }^{6}$ In this case, PRP schemes are mainly introduced in collective form, in general linking wages to plant or team performance.

${ }^{7}$ The Probit model in the first stage estimates the probability of being an adopter of FPS, while an OLS regression in the second stage estimates its effect on labor productivity.

${ }^{8}$ Data on the firms' labor force and industrial relations are drawn from the Employer and Employee Survey (RIL) provided by the ISFOL institute, while financial information comes from the AIDA - Bureau Van Dijk database.

${ }^{9}$ Damiani and Ricci (2014) analyze the same panel of Italian firms operating in manufacturing and service industries in 2005-2007, and find a positive association between unions' presence and the probability of adopting decentralized contracts or PRP schemes.
} 


\subsection{Unions and decentralized contracts in Italy}

Italy is characterized by a two-tier bargaining system, with a dominant sectoral tier and a supplementary decentralized tier where bargaining is usually carried out at the company/local level. ${ }^{10}$ The main objectives of the sectoral agreements (National Collective Labor Agreements, NCLAs) are to protect real wages and to set common economic and normative conditions for sectoral workers nationwide. At the decentralized level, it is possible to negotiate performance and productivity-related wage increases. In addition, the second level bargaining may address a number of additional matters, such as working hours, tasks, employment training, labor organization and union relations, in order to gain flexibility for organizational changes and competitiveness (Devicienti et al. 2016). ${ }^{11}$ Application to all workers in the firm of the conditions arrived at through bargaining at the decentralized level is the standard practice. Second-level bargaining is subject to the limits and provisions defined by the specific NCLAs applied in the productive unit. $^{12}$

Italian law gives the workers the right to join a union, engage in union activity and organize a plantlevel union representation structure. The main workplace representation body is the so-called unitary workplace union structures (Rappresentanze Sindacali Unitarie, RSU). The RSU includes features of works councils (e.g., worker representatives are elected by all the employees) but can also be associated with trade union bodies (e.g., worker representatives are usually elected from competing candidates on trade unions lists). Hence, in Italy, union and employee representation are entrusted to a single body (singlechannel representation), as opposed to a dual-channel system, where union delegates operate alongside works councils. ${ }^{13}$ Italian labor law makes it clear that setting up such representation bodies is at the initiative of a firm's employees, typically with moderate set-up costs and with an operational support that the territorial structures of the union confederations are always able and willing to provide. Worker representatives are able to negotiate at the plant level on issues delegated from the industry-wide level, and have the right to be informed and consulted. Unions and workers' representatives may be directly involved in the shaping of the firm's labor organization and hiring policies through participation at firm-level specific agreements on issues not already covered by NCLAs. Union influence may also be exerted through more informal consultation and involvement practices. This channel is likely to be relevant at the productive-unit level, where workers representatives interact with middle level managers (especially for small-medium size firms).

\footnotetext{
${ }^{10} \mathrm{~A}$ territorial level (mostly at the province level) also exists, but is typically confined to particular industries, e.g., construction and agriculture.

${ }^{11}$ There are no official data on the diffusion and content of decentralized bargaining. Survey data suggest that the coverage is at around 60 percent of employees and from 15 to 25 percent of firms (Damiani and Ricci, 2014), with greater incidence in manufacturing and larger firms. A large fraction of second-level agreements (over 60 percent) contain wage increases related to productivity gains, but agreements dealing with workplace organizational changes, performance-based human resource management practices and employment flexibility are not uncommon, and broadly cover the remaining 40 percent of cases.

${ }^{12}$ Decentralized agreements are only supplementary to, and applicative of, the NCLAs. The possibility of opting-out or derogating from NCLAs was formally introduced only recently, beyond the sample period we analyze.

${ }^{13}$ There is also an alternative plant-level union body (Rappresentanza Sindacale aziendale, RSA) elected by the members of a particular union. RSUs have tended to replace RSAs, which are usually found in smaller companies and in certain sectors like banking.
} 


\section{Methodology}

\subsection{Technical efficiency $\mathcal{G}$ bias correction}

In the present paper, we adopt a semi parametric approach using Data Envelopment Analysis, and its bias corrected version, to compute efficiency scores for a large sample of Italian firms operating in the manufacturing sector. The main advantage of using DEA is that it is not required to specify a form for the technology representing the production process, so that no assumptions are made for the shape of the production frontier. Moreover, DEA allows to compute a simple inefficiency measure also for a technology involving multiple outputs and multiple inputs: the frontier is directly derived from the data and all firms in the sample are evaluated through input or output distance functions ${ }^{14}$. We use an output-oriented approach that maximizes output levels given the present input bundle, because it is more suited for the second stage analysis. Let $x=\left(x_{1}, \ldots, x_{N}\right) \in R_{+}^{N}$ be inputs and $y=\left(y_{1}, \ldots, y_{M}\right) \in R_{+}^{M}$ be outputs, and suppose they are both freely disposable. Assuming that the output set $P(x)=\{(y, x): x$ can produce $y\}$ is closed and convex, the standard and general DEA efficiency score can be defined as:

$$
\lambda_{D E A}\left(x_{0}, y_{0}\right)=\sup \left\{\lambda \quad \mid \quad \lambda y_{0} \in P\left(x_{0}\right)\right\}
$$

Empirically, it can be estimated via linear programming through $\hat{\lambda}_{D E A}\left(x_{0}, y_{0}\right)$, by solving $\mathrm{K}$ linear programs, one for each firm in the sample. Following the Variable Return to Scale model proposed by Banker et al., (1984):

$$
\begin{aligned}
\hat{\lambda}_{D E A}\left(x_{0}, y_{0}\right) & =\max \lambda \\
\text { s.t. } \quad x_{0} & \geq \sum_{k=1}^{K} z_{k} X_{k}, \\
\lambda y_{0} & \leq \sum_{k=1}^{K} z_{k} Y_{k} ; \\
z_{k} & \geq 0 ; \\
\sum_{k=1}^{K} z_{k} & =1,
\end{aligned}
$$

where $\mathrm{k}$ indicates decision making units (DMUs) and $X$ and $Y$ are matrices of inputs and outputs. One of the main disadvantages of this deterministic approach is the absence of a stochastic error component. In fact, $\hat{\lambda}_{D E A}$ are biased by construction and overestimate the true technical efficiency level. Following Simar and Wilson (1998), the BIAS can be defined as:

$$
B I A S\left(\hat{\lambda}_{D E A}\left(x_{0}, y_{0}\right)\right)=E\left(\hat{\lambda}_{D E A}\left(x_{0}, y_{0}\right)\right)-\lambda_{D E A}\left(x_{0}, y_{0}\right)
$$

\footnotetext{
${ }^{14}$ For a detailed treatment of DEA, see Cooper et al., (2007).
} 
where $\lambda_{D E A}\left(x_{0}, y_{0}\right)$ represents the true unknown technical efficiency score. An estimate of the BIAS can be obtained using the homogeneous bootstrap method proposed by Simar and Wilson (1998), which assumes that the true production set boundaries lie to the left and above the piecewise linear frontier. The bias corrected DEA scores can therefore be derived as follows:

$$
\hat{\hat{\lambda}}_{D E A}\left(x_{0}, y_{0}\right)=\hat{\lambda}_{D E A}\left(x_{0}, y_{0}\right)-B I \hat{A} S_{B}\left(\hat{\lambda}_{D E A}\left(x_{0}, y_{0}\right)\right)
$$

The corrected efficiency scores in the output-oriented format are bounded below by 1 , a value that cannot be reached due to the correction procedure. Therefore, values near to 1 represent the most efficient firms in the sample, in terms of combining inputs in order to obtain output.

\subsection{Truncated regression model and separability conditions}

Explaining efficiency scores trough a classical regression model can be problematic for the unclear nature and the complex data generating process behind such scores. In their seminal paper, Simar and Wilson (2007) underline a complicated correlation structure for the residuals, and show the bias of the estimates performed using OLS or Tobit models, suggesting an estimation model that takes into account the truncated nature of the DEA scores. In particular, they recommend using a truncated regression model, to be estimated via Maximum Likelihood. In this paper, we use exactly that methodology, so that the empirical specification of the truncated regression is as follows:

$$
\hat{\hat{\lambda}}_{D E A}\left(x_{0}, y_{0}\right)=w_{k} \gamma+\varepsilon_{k} \geq 1, \quad k=1, \ldots K
$$

where $w_{k}$ represents a set of explanatory variables, and $\hat{\hat{\lambda}}_{D E A}\left(x_{0}, y_{0}\right)$ is the vector of estimated efficiency scores specific for each year. The application of Algoritm \#2 by Simar and Wilson (2007), to which we refer for any further details, can be resumed in a step by step procedure based on bootstrap and aimed at obtaining more robust and reliable confidence intervals for the estimated coefficients. Applications of such method on large samples are still scarce. Zelenyuk and Zheka (2006) apply it to a sample of 160 heterogeneous firms operating in different sectors, with the main aim of investigating, in the second stage, the influence of ownership and size on firm technical efficiency. Benito et al. (2014) use the truncated regression model to explain inefficiency of a large sample of Spanish municipal firms, while Falavigna and Ippoliti (2012) use it to analyze the efficiency of Italian hospitals over time. Biener et al. (2016) investigate the determinants of efficiency in the Swiss insurance sector including many firm characteristics as covariates, focusing on leverage and international diversification. However, the most recent developments in the field, see for example Simar and Wilson (2011) or Bâdin et al. (2012), highlight that the application of the truncated regression is valid only if the separability condition between the input-output space, used in the DEA phase, and the space of environmental variables $w$ (i.e. external factors $w$ that do not influence the shape of the frontier) holds. If the separability does not hold, the interpretation of the coefficients from the truncated regression becomes 
difficult, and the precision of estimates decreases as well. Testing separability represents a debated issue at the frontier of research in this field. In technical terms, separability implies that external factors $w$ influence the production process only through the conditional density function (i.e. the probability of lying on the frontier, for any given level of external factors), without influencing its support (Daraio et al., 2015). In other words, external factors should influence only the inefficiency level and not the shape of the frontier (i.e. the set of feasible input-output combinations are the same for different levels of such external factors). A first version of an empirical test for the validity of separability conditions has been proposed by Daraio et al. (2010 and 2015). The main idea is to compute unconditional and conditional DEA scores for different levels of external factors: if separability holds, the two sets of unconditional and conditional efficiency scores should not differ too much. ${ }^{15}$ This test has been applied here by considering qualitative/dichotomic external factors only, in order to eliminate the issue of bandwidth optimization, which is typical of conditional frameworks (Daraio and Simar, 2005).

\subsection{Endogeneity issues}

Concerning our two main variables of interest, the relationship of unions or DLCAs with technical efficiency may be potentially endogenous, e.g. if the best performing firms are also those in which unions or decentralized contracts are more likely to be present.

Endogeneity problems may be relevant for DLCA, because it is the firm itself that chooses to sign decentralized contracts, and that choice can be influenced by specific firms' or workforce's characteristics, which may also be related to efficiency performances. We try to solve this problem in two different ways. The first one is through the inclusion of additional control variables in the truncated regression model, to account for firm heterogeneity. The controls used are relatively standard and have already been used in previous works in the field (Bartelsman and Doms, 2000; Latruffe et al., 2008; Zelenyuk and Zheka, 2006; Bruno and Manello, 2015), so that we are relatively confident on the validity of the separability condition. In particular, we include controls for the size and the structure of firms, generally aimed at capturing the effect of scale economies or vertical integration, for the characteristics of the workforce (percentage of young workers, blue-white collars), as well as geographical and sectoral dummies.

The second way is more novel in the field of efficiency analysis. We try to remove any remaining endogeneity bias of the contract status' effect on efficiency by applying the propensity score based method proposed by Card and De La Rica (2006), in turn based on the results by Imbens (2004). In particular, the method is aimed at eliminating, or at least reducing, the bias that may arise if the presence of decentralized contracts is influenced by observed and unobserved firm-specific and worker heterogeneity. The approach requires that a first-stage model for the presence of DLCA is preliminarily estimated on a rich set of observed

\footnotetext{
${ }^{15}$ Daraio et al., (2015) derive an asymptotically normal test statistics, more complicated than a simple T-test for the complex structure of standard errors, and requiring a bootstrap procedure as highlighted by Kneip (2016).
} 
firm's and workforce's characteristics; a polynomial in the fitted probability (i.e., the propensity score for each firm) is then inserted among the explanatory variables (which already include the DLCA dummy) in the main regression used to explain the efficiency scores. Accordingly, we estimate the probability of adopting a decentralized contract through a Probit model, and we include the fitted probability, and its squared and cubed terms, as additional regressors in the Simar-Wilson truncated regression model. Essentially, the procedure amounts to controlling for the observed firm-level and workforce heterogeneity in a parsimonious but highly flexible way, thereby also minimizing biases from unobserved heterogeneity. ${ }^{16}$

Endogeneity problems for workplace unionization are also relevant in principle. However, we argue that they are not a practical concern in our application. Indeed, the structure of firm-level representativeness in Italy seems to partially guarantee that union organizations do not systematically select the best firms. As discussed by Breda (2015), the motivation can be traced to the underlying institutional mechanisms for setting up firm-level union representation bodies. In particular, in many countries of continental Europe the presence of unions is typically based upon the initiative of single employees and their willingness to become worker representatives, without the need for large initial investments by the candidate union. ${ }^{17}$ As a result, the probability of observing union's representation at the firm level becomes quasi-random, specially after major sources of firm heterogeneity (e.g., size, industry and firm past profitability) are already controlled for. ${ }^{18}$ Breda (2015) argues that this is indeed the case for France. Because of the substantial similarities in the Italian and French systems of industrial relations, we believe that these arguments can be used to discard concerns of large endogeneity biases in the estimated union effect. Nevertheless, in an attempt to further reduce any potential source of bias, in some of the specifications we will use the propensity score method for the workplace unionization variable, too.

\section{Data}

We use a large and representative sample of Italian firms (both corporations and general partnerships) drawn from the ISFOL's Employer and Employee Survey (RIL) ${ }^{19}$. The survey contains detailed information on each firm's labor force, industrial relations, investment and innovation activities. For our analysis, we focus on a sample of manufacturing firms drawn from the 2010 RIL survey, which contains rich information on the use of decentralized bargaining and of specific PRP schemes. The RIL survey, however, do not include

\footnotetext{
${ }^{16}$ This is more likely to happen whenever the omitted unobserved heterogeneity is correlated with the included observed heterogeneity, and points to the importance of using - as we do in section 5.3 - a rich specification for the propensity score.

${ }^{17}$ Differently from the US rules, a union does not have to obtain the majority of a firm's workforce in a Certification Election to gain firm-level representation and bargaining rights; it only needs find to a worker who is willing to act as a representative within the firm. This significantly reduces the need to incur in large monetary disbursements and other set-up costs by the candidate union.

${ }^{18}$ These aspects represent a deep difference with respect to other countries, where unions target most profitable and best performing firms (Brown et al., 2009).

${ }^{19}$ ISFOL stands for the Institute for the Development of Vocational Training of Workers, a national research institute that reports directly to the Ministry of Labour and Social Policy and provides support to the central government and local authorities
} 
reliable economic and financial information, which had to be recovered from another data source. Since each firm is identified by a tax code, we merged the RIL-ISFOL dataset with the AIDA dataset provided by Bureau Van Dijk, which contains detailed financial and economic data for all Italian corporations ${ }^{20}$. Inputs and outputs used in the DEA model, both derived by direct observation from financial statements, can be considered as reliable and representative of the real financial/economic position of the firm, as required by the law, but are less precise than physical quantities.

For this reason, we are particularly aware of the presence of possible outliers, which can cause instability in the solution of linear programs, so that a deep cleaning of the data is required. To be more specific, we firstly separate each two-digit ATECO2007 sector, so as to compare firms with a homogeneous technology. Secondly, we compute rough indicators of labor productivity (Value of Production/Labor Costs) and of mechanization (Physical Assets/Labor Costs). For each sub-sector, we only keep firms laying between the 1-99 percentiles. This procedure is aimed at eliminating firms with unreliable financial data. Moreover, we follow the method proposed by Simar (2003), to eliminate the remaining additional outliers ${ }^{21}$. The final sample includes 3,466 manufacturing firms which are classified in 20 homogeneous technologies, for which DEA models are computed separately by using a three-inputs and one-output technology. As to the inputs, fixed capital $(K)$ has been proxied by the total assets net of depreciation and amortizations, labor $(L)$ has been proxied by total labor costs (to overcome problems due to the identification of the number of full time equivalent workers and to the difference in the quality of the workforce). As for intermediate goods and services $(M)$, these have been proxied by the sum of raw material costs (net of inventories changes), services and the cost of leased assets. ${ }^{22}$ The latter input, collecting all goods and services provided by external suppliers, is uncommon in this kind of analysis, but has been included because the output considered $(Y)$ is the total value of production (revenues net of change in inventories), instead of value added. The motivation relies in the economic and financial crisis, which after 2008 had the effect of reducing value added to small (and sometimes negative) values. All financial variables have been deflated according to specific deflators provided by the national statistics institute (ISTAT). Table 1 reports descriptive statistics for the inputs and output variables.

Larger firms operate in Chemicals, Automotive and Metallurgy, while smaller firms in Wood and Printing. From a first analysis of the raw data, we notice that different combinations of capital and labor are used in different industries, motivating the computation of technical efficiency scores rather than labor productivity measures. In fact, DEA scores are computed considering the whole input bundle (capital, labor and intermediate goods) and separating different technologies (sectors), making them more precise than a simple output-input ratio. For example, as expected, the incidence of capital assets on revenues changes

\footnotetext{
${ }^{20}$ The cost of the merging is a loss in terms of number of firms, because in Italy only limited liabilities companies (SPA or SRL) are compelled to register financial statements.

${ }^{21}$ Outliers are mainly present in two sectors: Printing (code 18) and Repairing and maintenance (code 33).

${ }^{22}$ We thank an anonymous referee for useful suggestions on this aspect.
} 
Table 1: Descriptive statistics for inputs and output (year 2010)

\begin{tabular}{|c|c|c|c|c|c|}
\hline & \multirow[t]{2}{*}{ N. Firms } & \multicolumn{3}{|c|}{ Inputs $\left(10^{3}\right.$ euros $)$} & \multirow{2}{*}{$\begin{array}{l}\text { Output }\left(10^{3} \text { euros }\right) \\
\text { Value of production }\end{array}$} \\
\hline & & Interm. goods & Labor costs & Capital & \\
\hline Food & 459 & 26,175 & 3,541 & 7,920 & 32,852 \\
\hline Beverages & 71 & 34,032 & 3,668 & 11,201 & 43,886 \\
\hline Textiles & 143 & 14,020 & 3,968 & 4,933 & 19,656 \\
\hline Clothings & 118 & 22,430 & 3,572 & 3,594 & 28,623 \\
\hline Leather products & 95 & 21,683 & 3,452 & 2,828 & 28,407 \\
\hline Wood & 100 & 3,353 & 928 & 2,235 & 4,641 \\
\hline Paper & 78 & 18,692 & 3,439 & 9,143 & 24,062 \\
\hline Printing & 89 & 3,500 & 1,148 & 2,096 & 5,233 \\
\hline Chemicals and pharmaceuticals & 122 & 93,923 & 12,371 & 24,737 & 115,872 \\
\hline Rubber products & 141 & 24,724 & 5,338 & 7,952 & 32,172 \\
\hline Mineral products & 253 & 9,558 & 2,615 & 7,480 & 13,856 \\
\hline Metallurgy & 64 & 86,486 & 8,073 & 24,450 & 97,892 \\
\hline Metal products & 390 & 5,660 & 1,780 & 2,836 & 8,393 \\
\hline Computers and elctronics & 91 & 13,347 & 6,478 & 8,024 & 22,540 \\
\hline Electrical appliances & 122 & 28,606 & 6,464 & 5,445 & 39,399 \\
\hline Machinery & 390 & 18,367 & 4,271 & 3,864 & 25,415 \\
\hline Automotive and equipments & 85 & 72,780 & 19,027 & 16,429 & 103,098 \\
\hline Furniture & 351 & 6,257 & 1,492 & 2,550 & 8,299 \\
\hline Other manufacturing industries & 190 & 6,593 & 1,245 & 1,276 & 8,443 \\
\hline Repair and maintenance & 114 & 6,458 & 1,830 & 1,160 & 9,348 \\
\hline Total & 3466 & 20,367 & 3,875 & 6,123 & 26,752 \\
\hline
\end{tabular}

from around $15 \%$ for the automotive industry to $25 \%$ in the Chemicals or Beverages and to $40 \%$ in Wood or Printing.

\begin{tabular}{rrrr} 
Table 2: Number of firms with unions and decentralized contracts \\
\hline \hline & Unionized & Not Unionized & Total sample \\
\hline Decentralized LCA & 615 & 87 & 702 \\
Collective LCA & 492 & 2272 & 2764 \\
\hline Total sample & 1107 & 2359 & 3466
\end{tabular}

Our industrial relation variables of interest, as well other aspects related to the workforce, innovation and firms' internationalization, are obtained from the 2010 RIL Survey. Specifically, we created a dummy variable indicating whether workers have established any form of workers representation at the workplace (RSU or RSA) that is legally entitled to participate in the firm-level bargaining process. As shown in Table 2 , such a workplace representation is present in one third of the sample (1,107 firms). We also created a dummy variable indicating whether the firm and the unions have signed a decentralized labor agreement. As reported in Table 2, this occurs in $20 \%$ of the cases (702 firms). Among firms characterized by the presence of decentralized labor contracts, more than $90 \%$ adopt a PRP scheme, which remains one of the primary clauses discussed and bargained at the firm level. However, as shown in Table 3, its introduction is mainly pursued in a collective form (60\% adopt PRP only in collective form, $28 \%$ propose a mix of individual and collective PRP, and only $7 \%$ declare a wage integration entirely linked to individual performance). This suggests that Italian unions tend to avoid the use of individual incentive schemes or, even more, dislike the individual monitoring of performances.

While our industrial relation variables are obtained from the 2010 RIL, we use firms' financial statement variables for the period 2010-2012 for our DEA computations. We do so for three main reasons. First, by 
Table 3: PRP schemes among firms adopting a DLCA

\begin{tabular}{rr}
\hline PRP scheme & N. firms \\
\hline Collective & 411 \\
Collective \& individual & 184 \\
Only individual & 50 \\
\hline Firms adopting PRP & 645 \\
\hline
\end{tabular}

using firm's financial variables over a three year period we get three efficiency scores for each firm, one for each year. This increases the statistical efficiency of our second stage analysis (i.e. truncated regression phase), where three DEA scores for each firm have been used, and minimizes the impact of short-term fluctuations or measurement errors in single-year balance sheet entries. Therefore, observations from different years have been kept separated by considering year-specific frontiers. Second, we believe that the impact of unions and DLCA on firms' performance is hardly contemporaneous; more likely, it takes time to emerge and has some persistence over time. Since the RIL Survey 2010 portrays the firm's situation at the end of 2009, the performance for 2010 (based on data at the end of the year) and for subsequent years, should be influenced by the presence of unions/DLCAs. Finally, the fact that union and contracting status are lagged for the period 2010-2012 will further reduce endogeneity concerns.

\section{Results and discussion}

\subsection{Efficiency results}

Efficiency scores have been estimated using both $\mathrm{R}$ and the package FEAR (Wilson, 2008). The estimation has been performed separately for each year and for the 20 Ateco 2-digit codes. For each manufacturing activity, the bias correction method (based on the homogenous bootstrap procedure described in Simar and Wilson, 1998) has been applied separately, by running 2000 replications. The results are reported in Table 4. The efficiency scores are bounded below by 1 , a value that cannot be reached by fully efficient firms when the bias correction mechanism is implemented. Since the orientation of the DEA model is on outputs, each score can be interpreted as the potential increase in output obtainable if input bundles are combined efficiently. Notice the relatively high values of the average and median scores, which is largely due to the financial nature of data, by definition not so homogeneous also for firms operating in the same industry. Given that the DEA programs have been run separately for each sectoral sub-sample, the average and median efficiency scores relative to each industry cannot be immediately compared ${ }^{23}$. This is another reason in favor of the estimation of a truncated regression, which is able to eliminate, through the inclusion of sector dummies, the specific effect of each different reference frontier.

According to the figures reported in Table 4, there appears to be a substantial stability of heterogeneity among firms over time: on average, all firms in the sample remain at a rather constant distance from the

\footnotetext{
${ }^{23}$ The indicators collected in Table 4 can only be interpreted as measures of the heterogeneity of the sub-sample in relation to its specific best-practice frontier.
} 
Table 4: Bias corrected efficiency scores, computed sector by sector

\begin{tabular}{lcccccc}
\hline \multicolumn{1}{c}{ Industry } & \multicolumn{2}{c}{2010} & \multicolumn{2}{c}{2011} & \multicolumn{2}{c}{2012} \\
& Mean & Median & Mean & Median & Mean & Median \\
\hline Food & 1.313 & 1.316 & 1.288 & 1.291 & 1.238 & 1.231 \\
Beverages & 1.391 & 1.367 & 1.294 & 1.269 & 1.240 & 1.226 \\
Textiles & 1.253 & 1.242 & 1.329 & 1.301 & 1.302 & 1.244 \\
Clothings & 1.225 & 1.182 & 1.203 & 1.166 & 1.272 & 1.209 \\
Leather products & 1.176 & 1.151 & 1.190 & 1.172 & 1.187 & 1.151 \\
Wood & 1.304 & 1.250 & 1.298 & 1.218 & 1.255 & 1.210 \\
Paper & 1.151 & 1.125 & 1.180 & 1.150 & 1.200 & 1.156 \\
Printing & 1.352 & 1.323 & 1.364 & 1.317 & 1.388 & 1.349 \\
Chemicals and pharmaceuticals & 1.336 & 1.294 & 1.285 & 1.251 & 1.335 & 1.304 \\
Rubber products & 1.148 & 1.125 & 1.158 & 1.136 & 1.189 & 1.164 \\
Mineral products & 1.360 & 1.304 & 1.446 & 1.385 & 1.587 & 1.415 \\
Metallurgy & 1.160 & 1.123 & 1.116 & 1.086 & 1.144 & 1.112 \\
Metal products & 1.528 & 1.499 & 1.392 & 1.389 & 1.436 & 1.416 \\
Computers and electronics & 1.402 & 1.358 & 1.271 & 1.209 & 1.255 & 1.225 \\
Electrical appliances & 1.381 & 1.336 & 1.315 & 1.281 & 1.467 & 1.460 \\
Machinery & 1.483 & 1.460 & 1.369 & 1.334 & 1.483 & 1.431 \\
Automotive and equipments & 1.202 & 1.164 & 1.210 & 1.171 & 1.283 & 1.241 \\
Furniture & 1.297 & 1.283 & 1.337 & 1.319 & 1.394 & 1.327 \\
Other manufacturing industries & 1.282 & 1.252 & 1.261 & 1.248 & 1.319 & 1.311 \\
Repair and maintenance & 1.428 & 1.390 & 1.390 & 1.335 & 1.441 & 1.391 \\
\hline Total & 1.343 & 1.299 & 1.313 & 1.283 & 1.356 & 1.291 \\
\hline
\end{tabular}

specific yearly-estimated frontier. The highest values of inefficiency scores, both in term of mean and median, are recorded in 2011: a decreasing distance from the frontier suggests that the most disadvantaged firms (i. e. the followers) get closer to the best performers, which are lying on the frontier. Another important aspect is that the efficiency estimates are not much correlated to the number of observations relative to each manufacturing activity, so that our cleaning procedure appears to have been quite effective in eliminating outliers. The relative heterogeneity among firms (i.e. the average distance from their respective frontiers) is lower in Metallurgy, Paper, Rubber, Wood and Leather, while it is higher (i.e. highly efficient firms co-exist with a large plethora of less efficient units) in Metal products, Machinery and Repair and Maintenance. For Computers and Beverages, the inefficiency score recorded for 2010 drop in the analyzed period, and to some extent also the Automotive sector shares the same trend with a general situation that becomes more favorable also for followers firms operating in the automotive supply chain. On the contrary, sectors such as Electrical Appliances and Furniture show an increasing heterogeneity, suggesting that marginal firms have more difficulties to follow best performing firms.

\subsection{Second stage phase}

We turn now towards the investigation of the effect of industrial relations and labor contract characteristics on technical efficiency, and apply the truncated regression model depicted in section 3 . We use a homogeneous bootstrap procedure, repeating each truncated regression 200 times, for obtaining more reliable standard errors (see Simar and Wilson (2007) for further details. In order to increase the robustness of our results, at least on the two aspects of interest (i.e. unions and decentralized contracts), we replicate estimates under 8 different model specifications, including gradually the additional control variables reported 
in table 5. In all the reported estimates, the dependent variable is an efficiency score computed separately for each year and sector; time dummies are included to control for year specificities similarly to Biener et al. (2016), while sectoral dummies catch the sectoral fixed effect, shifting efficiency estimates according to each specific reference frontier. The results, which are reported in Table 6 , show that the sign and significance level of the two variables of interest are remarkably stable. Given the nature of the efficiency scores, proxing a distance from the reference frontier, a negative sign indicates a positive effect on efficiency.

Table 5: Descriptive statistics for second stage variables, 2010

\begin{tabular}{|c|c|c|c|}
\hline Variables & Definition & Mean & SD \\
\hline Size & Logarithm of employees & 3.30 & 1.32 \\
\hline Size Squared & Square of size & 12.62 & 10.37 \\
\hline Firm's age & Number of years from foundation & 25.15 & 15.53 \\
\hline Vertical Dis-integration & External costs over total costs & 0.71 & 0.14 \\
\hline Graduated employees (\%) & Share of graduated employees & 0.06 & 0.10 \\
\hline Young employees (\%) & Share of young employees & 0.24 & 0.23 \\
\hline White collar $(\%)$ & Share of white collar employees & 0.31 & 0.21 \\
\hline Export (\% of revenues) & Share of export over revenues & 0.23 & 0.29 \\
\hline Unionization rate & Share of unionized workers & 0.16 & 0.21 \\
\hline \multicolumn{4}{|l|}{ Dummies } \\
\hline Employees training & 1 if the firms offers traning & \multicolumn{2}{|c|}{$43 \%$} \\
\hline Patents & 1 if the firm registers patents (2007-2010) & \multicolumn{2}{|c|}{$12 \%$} \\
\hline North-West Italy & 1 if the firm is located in North-West & \multicolumn{2}{|c|}{$35 \%$} \\
\hline North-East Italy & 1 if the firm is located in North-East & \multicolumn{2}{|c|}{$31 \%$} \\
\hline Center Italy & if the firm is located in Center & \multicolumn{2}{|c|}{$18 \%$} \\
\hline South Italy & if the firm is located in South or in the Islands & \multicolumn{2}{|c|}{$16 \%$} \\
\hline
\end{tabular}

The two main aspects of interest are investigated through dummies: the first indicates firms adopting decentralized labor contract agreements (DLCAs), the second identifies firms where unions are present. We have included a set of time variant controls from the AIDA dataset (i.e. size, size squared, degree of vertical dis-integration) and a set of time invariant controls (i.e. regional and sectoral dummies, characteristics of managers, export share, labor force composition, innovation). Those variables appear gradually along the estimates in order to test the robustness and the stability of the results. Table 5 lists the full set of explanatory variables. As discussed in section 3.2, before running our truncated regression models, we test the validity of separability conditions for our simplest model, following the recent contribution by Daraio et al. (2015). In particular, we test separability for each sector and year (20 sectors and 3 years) including as external factors DLCA, Unions and Size $<15$ (i.e. the dummy indicating firms with less than 15 employees.). After having computed the asymptotically normal test statistics, we conclude that in $87 \%$ of the cases the null hypothesis of separability is not rejected, which implies that the truncated regression phase should lead to meaningful results.

The impact on efficiency is positive for decentralized contracts and negative for unions, and coefficients are always significant and with a magnitude which remains substantially stable across the different model specifications, even when the most complete set of control variables is included (model 5, our baseline specification). In particular, considering the presence of unions, the average level of inefficiency increases by 0.049 in magnitude (excluding model 1, the simplest, where the magnitude is lower), which corresponds to a $14 \%$ increase of the average inefficiency level in 2010 (1.343), the baseline year. The effect of adopting a 


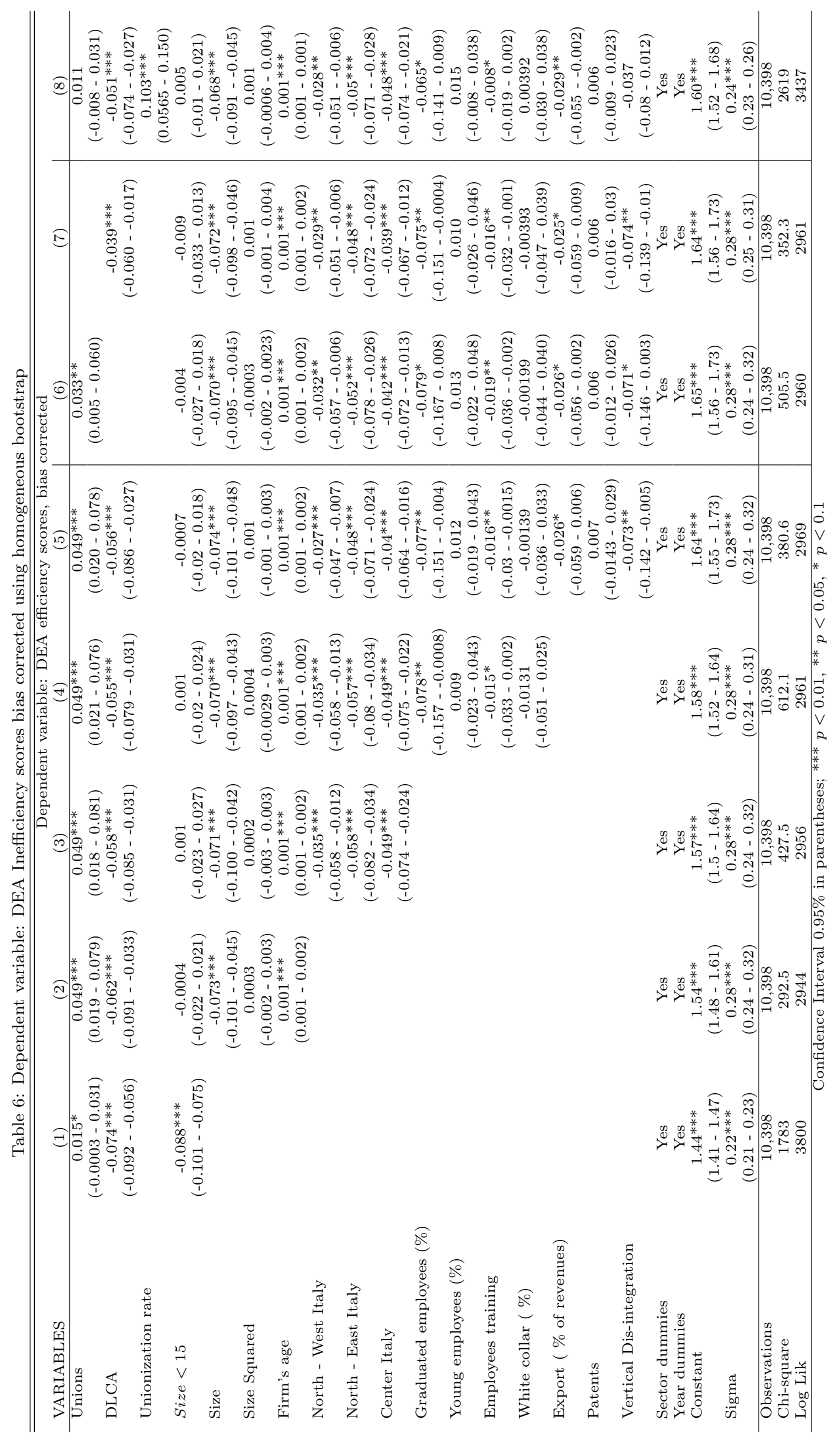


DLCA seems somewhat less stable across model specifications, increasing the efficiency indicator by 0.055 $0.062(16 \%-18 \%$ of the average inefficiency). The above findings for unions are in line in terms of magnitude (18\% for labor productivity and $13 \%$ for TFP) with Morikawa (2010), even if the sign is the opposite, while the results for DLCA are similar, in terms of sign and magnitude (20\%), to those reported by Addison et al. (2015), even if their left hand side variable is labor productivity.

The positive effect of DLCA remains slightly higher than the negative effect of unions. This suggests that, once the collective voice option has been formally recognized, the negative effect of the unions' monopoly face is almost completely compensated. Thanks to a better mix of organizational flexibility, wage incentives and a clearer definition of the union's role, aspects on which both the employees and the managers agree in written form through the stipulation of a DLCA, the drawbacks linked to union activity are substantially overcome. On the contrary, when the unions operating within the firm are unable or unwilling to (pre-)commit on well defined terms on such issues as labor organization, wage claims, cooperation with the management and internal conflicts smoothing, the detrimental effect on efficiency becomes more evident and the monopoly face of unions more likely to prevail, as argued by Kaufman (2004).

In the rest of this section, we briefly discuss the estimates for the remaining control variables, and report on the results of a number of robustness checks. The effect of size has been carefully considered. First, we include a dummy to isolate the effect on efficiency of small sized firms (up to 15 workers), for which the presence of unions and the adoption of DLCA is relatively rare ${ }^{24}$; the effect of such a dummy is, however, never significant across all the specifications, with the exception of the simplest model (1). Secondly, we include the logarithm of the number of employees and its square, in order to test for the presence of a non linear effect. As expected, and consistently with previous research dealing with DEA efficiency scores (Latruffe et al, 2008; Zelenyuk and Zheka, 2006), the effect of size on efficiency is positive and stable across models. The age of the firm, proxing its stability over time, shows a negative impact on technical efficiency, suggesting that younger firms are more apt to take advantage from technical progress. This evidence is probably linked to the issue of firm's maturity, which reduces the openness to new and risky technological innovation. The geographical location matters and shifts the average level of technical efficiency in favor of northern Italian regions, given that the reference group is represented by southern regions and islands.

Time invariant control variables catching workforce characteristics like education (share of graduated), age (share of young employees) and main task (share of white collars), introduced in regressions 4 and 5 , show mixed results and do not seem to deeply influence technical efficiency. This last set of variables, based on the RIL survey, refer to the end of 2009, but can be considered as proxies for the long run characteristics of the firm. However, when a firm invests in training activities for employees, the effect on efficiency becomes positive and significant; similarly firms exporting intensively show better performances in terms of efficiency.

\footnotetext{
${ }^{24}$ Firms employing less than 15 employees are also subject to softened employment protection legislation, as specified by the Italian Workers' Statute stipulated in 1970.
} 
Both aspects, employee training and export capacity, are two classical features of highly productive firms and this relationship is also confirmed regarding technical efficiency, except for the share of graduated employees. The coefficient estimated for the proxy of innovation (the patent dummy) is not statistically significant from zero. Finally, the level of vertical dis-integration, measured as the ratio of external costs over total costs, accounts for differences in outsourcing strategies and vertical boundaries and shows a strongly positive impact on technical efficiency, even after including services and leasing among the input of the efficiency model. This result suggests that outsourcing represents a valid instrument for increasing productivity levels, and is consistent with the results of Pieri and Zaninotto (2013) and Manello et al. (2016).

Additional estimates have been run as further robustness checks and the aforementioned evidence, in particular for what concerns the two main variables of interest, is substantially confirmed. Specifically, when we include an interaction term between unions and DLCA, the results are unchanged and the interaction variable remains not significant, highlighting the compensation effect of DLCA on the negative role of unions. Moreover, we run additional regressions, using size-class dummies, without significant changes in the main conclusions. Similarly, when we estimate separated truncated regression models excluding the 2010 year to reduce simultaneity concerns with unions or DLCA, the main findings remain virtually unchanged. ${ }^{25}$ Our results are also stable, in terms of sign and statistical significance, when one of the two variable of interest (unions or DLCA) is omitted, but the estimates are deeply downward biased: the single coefficient partially captures the effect on each variable, loosing the real trade-off between the two effects, as reported in models 6 and 7.

The last column of table 6 includes the unionization rate, a proxy of the union's power within the firm. The main findings remain the same, with an positive effect of DLCA and a negative (but poorly significant) effect of unions. The negative relationship between unions and technical efficiency is mainly captured by the unions' share rather than by the union dummy, with an effect that becomes even more negative as the percentage of unionized workers in the firm increases. This aspect will be further investigated in the following sections.

Finally, we fully exploit the information on the nature of PRP schemes (collective or individual) introduced through the DLCA. The general result is that estimates are substantially robust to the inclusion of dummies accounting for the type of PRP schemes (models 9 through 12), while the new regressors are not found to influence the observed efficiency level, highlighting that, rather than wage settings it is the whole spectrum of contractual clauses that matters for efficiency. Results from those estimates are reported in Appendix A, table 9 .

${ }^{25}$ These additional results are not reported in the paper, but they are available upon request. 


\subsection{Controlling for the probability of DLCA's adoption}

The presence of firm-specific aspects that influence the probability of signing a DLCA can introduce potential bias in the estimated positive effect from such contracts. As previously discussed, we try to solve the problem by introducing a low order polynomial function of the predicted probability of adopting a decentralized contract at firm level, following the methodology proposed by Card and De La Rica (2006). The main advantage is that all the relevant information from additional workforce's and firm's characteristics are condensed in a one-dimensional indicator that flexibly and parsimoniously controls for such additional variables and their interactions. We run a Probit model on the probability of observing DLCA at the firm level using as covariates the fraction of female and temporary workers, the share of educated and young employees, the incidence of white-blue collars, the share of employees trained on the job, firm's size and age, and past average profitability levels ${ }^{26}$. Finally, we include controls for regions and sectors. The predicted probability, along with its square and its cube, have been included as additional regressors in the SimarWilson truncated regression model to partially discard the effect on technical efficiency attributed to the potentially higher ex-ante probability of signing DLCA for some firms.

\begin{tabular}{rcc} 
Table 7: Propensity score value added in the Simar-Wilson truncated regression \\
\hline \hline VARIABLES & p-score on DLCA & p-score on Unions \\
\hline Unions & $0.0545^{* * *}$ & $0.0445^{* * *}$ \\
& $(0.0219-0.0871)$ & $(0.0163-0.0726)$ \\
DLCA & $-0.0514^{* * *}$ & $-0.0597^{* * *}$ \\
& $(-0.0807--0.0220)$ & $(-0.0902--0.0293)$ \\
Propensity score & $0.503^{* *}$ & 0.101 \\
& $(0.0762-0.930)$ & $(-0.272-0.473)$ \\
Propensity score squared & $-1.120^{* *}$ & -0.585 \\
& $(-2.029--0.212)$ & $(-1.441-0.271)$ \\
Propensity score cubed & $0.793^{* *}$ & 0.538 \\
& $(0.168-1.417)$ & $(-0.103-1.180)$ \\
Controls & Yes & Yes \\
Sector dummies & Yes & Yes \\
Year dummies & Yes & 10,398 \\
Observations & 10,398 & 523.3 \\
Chi-square & 680.7 & 2971.5 \\
Log Lik & 2973 & $<0.1$. Even if not \\
\hline Confidence Interval $0.95 \%$ in parentheses; ${ }^{* * *} p<0.01,{ }^{* *} p<0.05,{ }^{*} p<<$ & $<0$.
\end{tabular}

The results from table 7 once again confirm the robustness of our main findings. In comparison to our baseline model (table 6, model 5), the estimated coefficient for DLCA obtained with the propensity score based method decreases approximately by $10 \%$ (from -0.056 to -0.051 ), in line with what reported by Card and De La Rica (2006) for their application. The coefficients for the remaining variables ${ }^{27}$, as well as for the presence of unions, remain substantially stable when the propensity score terms are included. Therefore, even after controlling for the ex-ante probability of adopting decentralized contracts (which partially solve the endogeneity issues), the effective presence of DLCA shows a positive and significant effect on efficiency

\footnotetext{
${ }^{26}$ We use Return on Sales averaged for the period 2007-2009 as a proxy of past profitability. If financial data are missing for previous periods, we use the 2010 value.

${ }^{27}$ Those coefficients are not reported here for simplicity, but are available upon request.
} 
(15\% in relative terms). A similar procedure has also been applied for the presence of unions, by estimating a probit model that uses the same covariates listed above. The results of column 3 show that the inclusion of propensity score terms reduces the estimated coefficient on the dummy of interest by 10\%, and results are stable also for the other variables. In both the case of DLCAs and unions, therefore, adding the propensity scores terms leaves the main messages unchanged.

\subsection{Extensions: the role of international competition, debt and assets' rigidity}

As shown in the previous sections, the presence of unions in the workplace has a significant negative influence on efficiency, which is virtually compensated whenever a decentralized labor contract agreement has been formally stipulated between the managers and the workers' representatives. However, the relative power of unions may be drastically different according to firms' characteristics or to some specific strategies pursued by firms. Previous literature highlights three main channels through which unions can suffer a substantial limitation of their power: exposure to international competition, low degree of capital sunkness/rigidity and high levels of debt. These three aspects have been extensively investigated by empirical papers, also recently, but the main focus has been on labor outcomes (such as wage differentials) or on firms financial outcomes (such as investment or cash flows), rather than on their role in limiting the adverse union effect on firm efficiency.

A higher exposure to international competition is expected to increase managers' bargaining power through the credible threat of de-localizing production activities or via the lower mark-up in the foreign markets. Felbermayr et al. (2014) investigate the influence of export intensity on rent-sharing and find lower wages for firms more exposed to international trade, highlighting a lower unions' power, mainly due to the diminishing markups in foreign markets. The effect should be even stronger if firm have already de-localized part of production processes abroad.

Bronars and Deere (1991) argue that increasing the level of debt is a specific strategy pursued by managers to reduce the amount of profits potentially appropriable by employees, as well as the unions' bargaining power before negotiation. Matsa (2010), analyzing data on US firms for the 1970s and the 1990s, finds a significant relation between debt structure and unions' power, confirming that firms increase debt to limit the bargaining power of their employees.

Finally, the so called hold-up theory suggests that, in the presence of large irreversible investments (as in the case of sunk costs or very illiquid assets) and incomplete contracts, the union bargaining power is higher and the firm is more vulnerable to unions' opportunistic behavior in wage negotiations, which may lead to a reduction of future investments. Recently, Cardullo et al. (2015) provide evidence on the empirical relevance of this holdup problem using international sector-level data. They find a negative effect of unions' power on investment per worker, observing a stronger effect in sectors characterized by a higher presence of sunk or rigid capital. 
From these previous studies, we can expect a stronger bargaining power of unions when the exposure to international competition is limited, when the invested capital is sunk or rigid and when level of debt is not high. In such cases, the margin of negotiation with the management is wider, so that we expect a higher (negative) impact on efficiency. The empirical strategy is based on a pre-identification of the subset of firms in which the bargaining power of unions should be more limited and a separate estimation of the same truncated regression model across the two groups, comparing the magnitude of the usual union-dummy coefficient. We replicate the same procedure by dividing the sample according to the three aforementioned aspects, and by identifying three groups, sometimes partially overlapped, where union bargaining power is high (low).

Table 8 reports three sets of results, all based on the richest specification of Table 6 (model 5). The first part of Table 8 (columns 2 and 3) analyzes the exposure to international competition. Firms have been divided in two groups on the basis of their exposure to international markets: firms that already delocalize production phases as well as firms directly investing in foreign countries are identified as highly exposed to international competition. The estimated effect of unions' presence across the two groups differ substantially. As expected, for firms intensively (marginally) exposed to international competition, unions do not reduce efficiency (reduce efficiency by 0.036). This is consistent with the idea that, when the firm does not operate directly abroad, the threat of off-shoring is less credible and mark-ups may be higher, with a stronger bargaining power of unions.

The second part of table 8 (columns 4-5) is focused on firms' debt structure. The whole sample has been divided into two groups on the basis of the leverage index, computed as external debt over equity in 2010. The results confirm a higher effect (0.04) of unions on inefficiency for firms with lower debt. Also in this case the result is coherent with previous findings, and confirms that a higher debt exposure reduce unions' bargaining power and limits the negative impact on technical efficiency.

Finally, the last two columns of Table 8 are focused on the role of capital rigidity. We use a firm-level measure of physical capital intensity, the ratio of tangible assets over total assets. ${ }^{28}$ Also in the case of physical capital intensity, the effect of unions on inefficiency is higher (0.048 versus 0.018$)$ for the group characterized by higher rigidity.

Despite a direct causal effect of each single aspect influencing unions' power and technical efficiency should be identified with care for the arbitrary divisions of the sample, the substantial coherence of the estimated coefficients across different models increases the interest of our results, and our confidence on their general validity. When the characteristics of the firms or the managerial strategies are such that the bargaining power of unions is limited, the effective presence of unions shows a substantially lower negative impact on technical efficiency, with lower coefficients (and in some cases even not significant) with respect

\footnotetext{
${ }^{28}$ The threshold used to identify firms characterized by a rigid capital structure is the average value, corresponding to a ratio equal to 0.26 . When using the median of the distribution to separate the two groups, we obtain very similar results.
} 


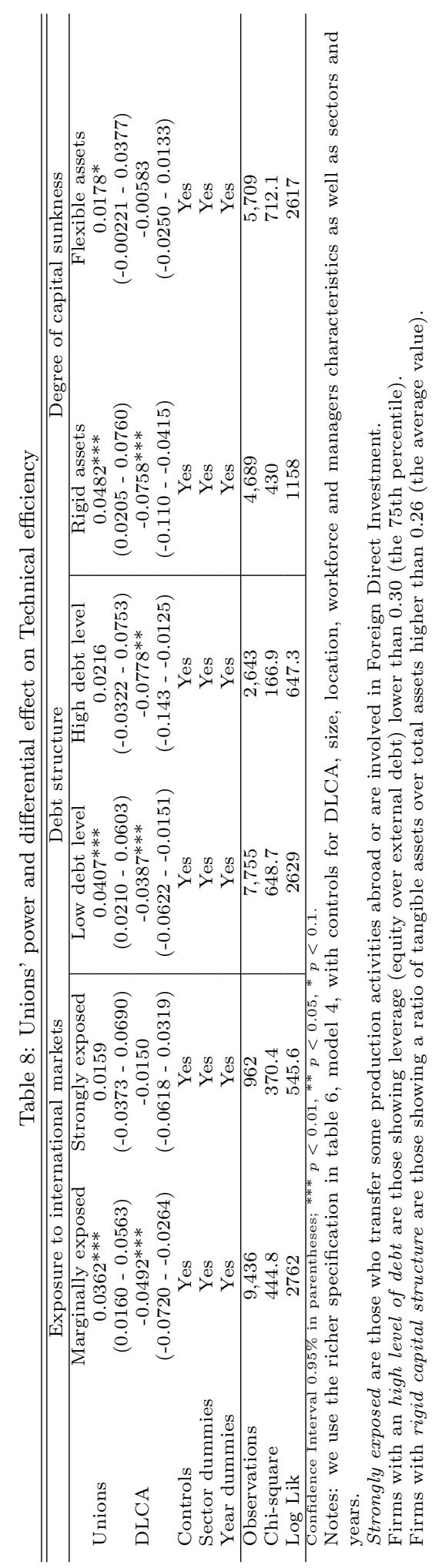


to the ones reported for the high unions' power sub-samples.

Overall, our results suggest that, while workplace unionization decreases efficiency, factors limiting unions' bargaining power, such as higher exposure to international markets, higher debt and flexible assets, reduce this detrimental effect. That evidence is in line with our finding reported in table 6 column 8 , which shows how unions supported by a small number of members (i.e. where the unionization rate within the firm is low) have a more limited effect on technical efficiency.

\section{Concluding remarks}

Despite a vast theoretical and empirical literature, the relationship between unions and productivity remains vague, with numerous contributions supporting both positive and negative effects. The conflicting results partly reflect institutional, country and sector specificities, as well as the methodology used to measure productivity and estimate the impact of unions. We contribute to this debate by proposing one of the first applications of efficiency analysis to labor economics issues, investigating the effect of unions and decentralized bargaining on technical efficiency. In particular, we adopt a semi-parametric DEA approach for estimating efficiency scores on a large sample of Italian firms operating in the manufacturing sector. We devote specific attention to compare firms that adopt similar technologies by running 20 separate frontiers and by analyzing efficiency scores through a truncated regression model. Our main result is that the presence of unions within the firm represents a source of inefficiency that can be reduced or almost neutralized through the adoption of decentralized labor contract agreements. We view these findings as evidence that the negative union effect, which remains significant and stable across all the robustness checks implemented, strongly prevails where unions are present in the firm without a formal commitment (i.e., the adoption of a DLCA) to limit its conflictual/monopoly face with the management. Furthermore, our findings suggest that the relative power of unions plays an important role too. After having classified firms according to their differential exposure to international trade, degree of external debt or rigidity of the capital invested, all factors limiting the unions' bargaining power, we find that the negative effect of unions is much lower (if it exists) for firms producing abroad, for firms with high debt and for firms with more flexible assets.

Our findings support the view that the adoption of decentralized bargaining, which once expressed in a formal contract may prove effective in limiting unions' power and its discretionary and opportunistic behavior, acts as an efficiency enhancing factor, as recently argued also by the European Commission. On the one hand, DLCAs counterbalance the presence of unions and reduce the risk of potential appropriations of the firm's returns by its employees. On the other hand, the additional bargained flexibility introduced by DLCAs increases the possibilities of combining inputs, and sustains technical efficiency not only through performance related pay clauses.

In terms of policy implications, we suspect that the current model of Italian union representation broadly fails in supporting the collective-voice face of unionism, if internal conflicts are not smoothed so as to create 
the conditions for signing decentralized contracts. In the absence of such agreements, workplace unionization is unlikely to represent an efficiency-enhancing factor, lead to improved industrial relations and contribute to increase reciprocal trust and cooperation between employees and managers. In our view, policies to favor the adoption of DLCAs should be part of the broader set of interventions aimed at reversing the country's long-standing productivity crisis. While our findings are specific to the Italian case, we believe they are relevant also for other countries of continental Europe, which tend to be characterized by a similar system of industrial relations.

Despite our results survived to various robustness and specification checks, it is important to be aware of a number of limitations of our analysis. First, our financial data are at the firm-level, rather than at the plant level. While for a country such as Italy, characterized by a vast majority of SME enterprises, the problem of multisite firms is unlikely to significantly impact on our results, further research is needed on this issue. It would also be important to observe the content of DLCAs (i.e., the various wage and non-wage issues covered by these contracts), rather than a simple dichotomous indicator for the presence of a DLCAs. Clearly, the availability of richer data would allow us to shed additional light on such issues and to further qualify our results.

Second, there are some methodological issues that should receive deeper attention in future research. For instance, while the labor economics literature puts much emphasis on how to deal with the potential endogeneity of "environmental variables" such as workplace unionization and the adoption of decentralized contracts, the literature on non-parametric approaches to technical efficiency (e.g., DEA) is putting such issues on the forefront of the research agenda only recently (e.g., Simar et al., 2016; Cordero et al., 2015). In this respect, our paper presents a combination of techniques that we believe might represent a useful framework for similar research themes. First, we conducted the test of separability conditions recently proposed by Daraio et al., (2015). Our discussion of the Italian institutional setting and the results of these tests, lent support to the "separability" of our environmental variables. Second, we proposed to combine a propensity score based method with the truncated regression model to deal with the possible endogeneity of unions and DLCA with respect to technical efficiency arising in the second second stage of our analysis. This is a simple and parsimonious method for dealing with omitted variable bias when, as in our case, the data offer a rich set of past observed information on firm economic performance and financial situation that might be correlated with workplace unionization and the adoption of DLCAs. While our results received additional support when using the propensity score method, it should be noted that a limitation of this approach is that it does not explicitly deal with the potential estimation biases arising from unobserved heterogeneity. At a more general level, we believe that the cross fertilization between efficiency analysis and issues traditionally dealt within the labor economic literature appears to be a promising avenue for future research. 


\section{References}

Addison J. and Hirsch B., 1989. Union effects on productivity, profits, and growth: has the long run arrived?. Journal of Labor Economics 7: 72 - 105.

Addison J., Teixtiera P., Evers K. and Bellmann L., 2015. Pacts for employment and competitiveness as a role model? Their effects on firm performance. IZA Discussion Papers No. 9323.

Antonietti R., Pini P. and Antonioli D., 2014. Flexible pay systems and labour productivity: Evidence from Emilia-Romagna manufacturing firms. Working Papers n. 2014143, University of Ferrara, Department of Economics.

Bâdin L., Daraio C. and Simar L., 2012. How to measure the impact of environmental factors in a nonparametric production model. European Journal of Operational Research, 223(3): 818 - 833.

Bandiera O., Barankay I. and Rasul I., 2005. Social preferences and the response to incentive: evidence from personnel data. Quarterly Journal of Economics 120(3): 917 - 962.

Banker R. D., Charnes A. and Cooper W. W., 1984. Some models for estimating technical and scale inefficiencies in Data Envelopment Analysis. Management Science, 30(9): 1078 - 1092.

Bartelsman, E.J. and Doms M., 2000. Understanding productivity: lessons from longitudinal microdata. Journal of Economic Literature, XXXVIII: 569 - 594.

Bellmann, L., Gerner H. D., and Hbler O., 2015. Investment under Company-Level Pacts before and during the Great Recession. Economic and Industrial Democracy 36(3): 501 - 522.

Benito B., Solana J. and Moreno M.R., 2014. Explaining efficiency in municipal service providers. Journal of Productivity Analysis 42(3): 225 - 239.

Bennett J. and Kaufman B. (eds), 2007. What do unions do? A 20-year perspective. Transaction Publisher, New Brunswick.

Biener C., Eling M. and Wirfs J.H., 2016. The determinants of efficiency and productivity in the Swiss insurance industry. European Journal of Operational Research 248(2): 703 - 714.

Breda T., 2015. Firms' rents, workers' bargaining power and the union wage premium. The Economic Journal 125: 1616 - 1652.

Bronars S.G. and Deere D.R., 1991. The threat of unionization, the use of debt, and the preservation of shareholder wealth. The Quarterly Journal of Economics 106(1): 231 - 254.

Brown W., Bryson A. and Forth J., 2009. Competition and the retreat from collective bargaining. Cambridge University Press, Cambridge.

Bruno C. and Manello A., 2015. Benchmarking and effects of reforms in the fixed telecommunications industry: A DDF approach. Telecommunications Policy 39(2): 127 - 139.

Card D., Devicienti F. and Maida A., 2014. Rent - sharing, holdup and wages: evidence from matched panel data. Review of Economic Studies, 81(1): 84 - 111.

Card D. and De La Rica S., 2006. Firm - level contracting and the structure of wage in Spain. Industrial and Labor Relation Review 59 (4): 573 - 592.

Cardullo G., Conti M. and Sulis G., 2015. Sunk capital, unions and the hold-up problem: theory and evidence from cross-county sectoral data. European Economic Review 76(C): 253 - 274.

Chintrakarn P. and Chen Y., 2010. Do unions impact efficiency? Evidence from the US manufacturing sector. Contemporary Economic Policy, 29(3): 431 - 440.

Cooper W.W., Seidorf L.M. and Tone, K., 2007. Data Envelopment Analysis. A comprehensive text with models, Application References and DEA-solver Software. Springer Edition, Berlin.

Cordero J.M., Santin D. and Sicilia G., 2015. Testing the accuracy of DEA estimates under endogeneity through a Monte Carlo simulation. European Journal of Operational Research 244: 511 - 518.

Damiani, M. and Ricci, A., 2014. Decentralized bargaining, and performance related pay: Evidence from a panel of Italian firms. International Journal of Manpower, 35(7): 1038 - 1058.

Damiani M., Pompei F. and Ricci A., 2016. Performance related pay, productivity and wages in Italy: a quantile regression approach.International Journal of Manpower, 37(2): 344 - 371.

Daraio C. and Simar L., 2005. Introducing environmental variables in nonparametric frontier models: a probabilistic approach. Journal of Productivity Analysis 24(1): 93 - 121. 
Daraio, C. and Simar, L., 2007. Advanced robust and nonparametric methods in efficiency analysis. Methodology and applications. New York: Springer.

Daraio, C., Simar L., and Wilson P., 2010. Testing whether two-stage estimation is meaningful in nonparametric models of production. Discussion paper 1031, Institut de Statistique, Universit Catholique de Louvain, Louvain-la-Neuve, Belgium.

Daraio C., Simar L. and Wilson P., 2015. Testing the separability condition in two-stage nonparametric models of production. LEM working paper 2015/21, LEM - Laboratory of Economics and Management, Institute of Economics Scuola Superiore Sant'Anna.

Devicienti F., Naticchioni P. and Ricci, A., 2016. Temporary employment, demand volatility and unions: Firm-level evidence. Industrial and Labor Relation Review, forthcoming.

Doucouliagos H. and Laroche P., 2003. What do unions do to productivity? A meta-analysis. Industrial Relations 42(4): 650 - 691.

Doucouliagos H. and Laroche P., 2006. Human resource practices, unionization and the organizational efficiency of French industry, in Lewin D. and Kaufman B. (ed.) Advances in industrial labor relations, Volume 15: 67 - 102, Emerald Group Publishing Ltd, Bingley.

Doucouliagos H. and Laroche P., 2009. Unions and profits: a meta-regression analysis. Industrial Relations 48(9): 146 - 183.

Fairris D. and Askenazy P., 2010. Works councils and firm productivity in France. Journal of Labor Research, 31(3): 209 - 229.

Falavigna G. and Ippoliti R., 2012. Efficiency of the medical care industry: Evidence from the Italian regional system. European Journal of Operational Research, 217(3): 643 - 652.

Felbermayr G., Hauptmann A. and Schmerer H.J. 2014. International trade and collective bargaining outcomes: evidence from German Employer-Employee data. The Scandinavian Journal of Economics 116(3):820 - 837.

Freeman R. and Medoff J., 1984. What do unions do? Basic Books, New York.

Gielen A., Kerkhofs M. and van Ours J., 2010. How performance related pay affects productivity and employment. Journal of Population Economics 23(1): 291 - 301.

Greer M., 2009. Is it the labor unions' fault? Dissecting the cause of the impaired technical efficiencies on the legacy carrier in the United States. Transportation Research Part A, 43(9): 779 - 789.

Hirschman A., 1970. Exit, voice and loyalty. Harvard University Press, Cambridge MA.

Hübler O. and Jirjahn U., 2003. Work councils and collective bargaining in Germany: the impact on productivity and wages. Scottish Journal of Political Economy, 50(4): 471 - 491.

Imbens G., 2004. Non parametric estimation of average treatment effect under exogeneity: A review. Review of Economics and Statistics 86(4): 4-29.

Kaufman B., 2004. What unions do: insight from economic theory. Journal of Labor Research 25(3): $351-382$.

Kneip A., Simar L. and Wilson P., 2016. Testing hypotheses in nonparametric models of production. Journal of Business Economics and Statistics 34(3): 435 - 456.

Kuhn, P. 1998. Unions and the economy: What we know; what we should know. Canadian Journal of Economics 31(5): 103356.

Latruffe, L., Davidova, S. and Balcombe K., 2008. Application of a double bootstrap to investigation of determinants of technical efficiency of farms in Central Europe. Journal of Productivity Analysis, 29(2): $183-191$.

Lucifora C. and Origo F., 2015. Performance-related pay and firm productivity: evidence from a reform in the structure of collective bargaining. Industrial and Labor Relations Review, 68 (3): 606 - 632.

Manello A., Calabrese G. and Frigero P., 2016. Technical efficiency and productivity growth along the automotive value chain: evidence from Italy, Industrial and Corporate Change, 25 (2): 245 - 259.

Matsa A.D., 2010. Capital structure as a strategic variable: evidence from collective bargaining. Journal of Finance 65(3), 1197 - 1231.

Metcalf D., 2003. Unioins effect on productivity, profitability and investment, in Addison J. and Schnabel C. (eds), International Handbook of trade unions, Edward Elgar, London. 
Morikawa M., 2010. Labor unions and productivity: an empirical investigation using Japanese firm-level data. Labour Economics 17(6): 1030 - 1037.

Muller S., 2012. Work council and establishment productivity. Industrial and Labor Relations Review $65(4): 880-898$.

Muller S., 2015. Work council and labour productivity: looking beyond the mean. British Journal of Industrial Relations 53(2): 308 - 325.

Origo F., 2009. Flexible pay, firm performance and the role of unions. New evidence from Italy. Labour Economics, 16(1): $64-78$.

Pencavel J., 2002. The surprising retreat of unions in Britain, in Bundell R., Card D. and Freeman R. (eds.), Seeking a premier league economy, University of Chicago Press for NBER, Chicago.

Pieri, F. and Zaninotto, E., (2013). Vertical integration and efficiency: an application to the Italian machine tool industry. Small Business Economics, 40(2): 397 - 416.

Schank, T., Schnabel, C. and Wagner, J. 2004. Works councils: sand or grease in the operation of German firms. Applied Economics Letters, 11: 159 - 161.

Schedlitzki D., 2002. German works councils, employee involvement programs, and their impact on establishment productivity. Centre for Economic Performance Working Paper No. 1191, London School of Economics.

Simar L., 2003. Detecting outliers in frontier models: a simple approach. Journal of Productivity Analysis 20(3):391 - 424 .

Simar L., Vanhems A. and Van Keilegom I., 2016. Unobserved heterogeneity and endogeneity in nonparametric frontier estimation. Journal of Econometrics 190: 360 - 373.

Simar L. and Wilson P.W., 1998. Sensitivity analysis of efficiency scores: how to bootstrap in nonparametric frontier models. Managerial Science 44(1):49 - 61.

Simar L. and Wilson P.W., 2007. Estimation and inference in two-stage, semi-parametric models of production process. Journal of Econometrics 136 (1): 31 - 64

Simar L. and Wilson P.W., 2011. Two-stage DEA: caveat emptor. Journal of Productivity Analysis 36(2): $205-21$.

Ton Z. and Huckman R.S., 2008. Managing the impact of employee turnover on performance: The role of process conformance. Organization Science 19(1): 55 - 68.

Wilson, K.G. 1995. The impact of unions on United States economy-wide productivity. New York: Garland.

Wilson P.W., 2008. Fear 1.0: a software package for frontier efficiency analysis with R. Socio Economic Planning Science 42(4): 247 - 254.

Zelenyuk V. and Zheka V., 2006. Corporate governance and firms efficiency: the case of a transitional country, Ukraine. Journal of Productivity Analysis 25 (1-2): 143-157.

Zschille M., 2015. Consolidating the water industry: an analysis of the potential gains from horizontal integration in a conditional efficiency framework. Journal of Productivity Analysis, 44: 97-114. 


\section{Appendix A1}

Table 9: The interaction of DLCA, PRP schemes and unions

\begin{tabular}{|c|c|c|c|c|}
\hline VARIABLES & $\overline{(9)}$ & $\overline{(10)}$ & $\overline{(11)}$ & $\overline{(12)}$ \\
\hline Unions & $0.0497^{* * *}$ & $0.0501^{* * *}$ & $0.0495^{* * *}$ & $0.0498^{* * *}$ \\
\hline & $(0.0188-0.0806)$ & $(0.0219-0.0783)$ & $(0.0201-0.0788)$ & $(0.0217-0.0780)$ \\
\hline DLCA & $-0.0585^{* * *}$ & $-0.0473^{* * *}$ & $-0.0570^{* * *}$ & $-0.0447 * * *$ \\
\hline Individual PRP & $\begin{array}{c}(-0.0880--0.0290) \\
0.00112 \\
(-0.0246-0.0269)\end{array}$ & $(-0.0809--0.0138)$ & $\begin{array}{c}(-0.0869--0.0271) \\
0.00125 \\
(-0.0292-0.0317)\end{array}$ & $(-0.0738--0.0156)$ \\
\hline Collective PRP & & $\begin{array}{c}-0.0195 \\
(-0.0476-0.00849)\end{array}$ & & $\begin{array}{c}-0.0214 \\
(-0.0492-0.00649)\end{array}$ \\
\hline Size $<15$ & $\begin{array}{c}0.00183 \\
(-0.0205-0.0242)\end{array}$ & $\begin{array}{c}0.00178 \\
(-0.0206-0.0241)\end{array}$ & $\begin{array}{c}-0.000775 \\
(-0.0238-0.0222)\end{array}$ & $\begin{array}{c}-0.000848 \\
(-0.0246-0.0229)\end{array}$ \\
\hline Size & $\begin{array}{c}-0.0713^{* * *} \\
(-0.0981--0.0446)\end{array}$ & $\begin{array}{c}-0.0712^{* * *} \\
(-0.0976--0.0448)\end{array}$ & $\begin{array}{c}-0.0748^{* * *} \\
(-0.106--0.0435)\end{array}$ & $\begin{array}{c}-0.0747^{* * *} \\
(-0.104--0.0457)\end{array}$ \\
\hline Size Squared & $\begin{array}{c}0.000202 \\
(-0.00301-0.00341)\end{array}$ & $\begin{array}{c}0.000183 \\
(-0.00300-0.00337)\end{array}$ & $\begin{array}{c}0.00111 \\
(-0.00187-0.00409)\end{array}$ & $\begin{array}{c}0.00110 \\
(-0.00197-0.00417)\end{array}$ \\
\hline Firm's age & $\begin{array}{c}0.00165^{* * *} \\
(0.00111-0.00219)\end{array}$ & $\begin{array}{c}0.00164^{* * *} \\
(0.00109-0.00220)\end{array}$ & $\begin{array}{c}0.00165^{* * *} \\
(0.00106-0.00224)\end{array}$ & $\begin{array}{c}0.00164 * * * \\
(0.00106-0.00222)\end{array}$ \\
\hline North - West Italy & $\begin{array}{c}-0.0357^{* * *} \\
(-0.0582--0.0133)\end{array}$ & $\begin{array}{c}-0.0358^{* * *} \\
(-0.0591--0.0125)\end{array}$ & $\begin{array}{c}-0.0276^{* *} \\
(-0.0519--0.00329)\end{array}$ & $\begin{array}{c}-0.0276^{* *} \\
(-0.0514--0.00388)\end{array}$ \\
\hline North - East Italy & $\begin{array}{c}-0.0582^{* * *} \\
(-0.0809--0.0355)\end{array}$ & $\begin{array}{c}-0.0579 * * * \\
(-0.0827--0.0331)\end{array}$ & $\begin{array}{c}-0.0480^{* * *} \\
(-0.0718--0.0242)\end{array}$ & $\begin{array}{c}-0.0476 * * * \\
(-0.0710--0.0242)\end{array}$ \\
\hline Center Italy & $\begin{array}{c}-0.0494^{* * *} \\
(-0.0747--0.0241)\end{array}$ & $\begin{array}{c}-0.0493 * * * \\
(-0.0749--0.0237)\end{array}$ & $\begin{array}{c}-0.0404 * * * \\
(-0.0691--0.0116)\end{array}$ & $\begin{array}{c}-0.0402 * * * \\
(-0.0676--0.0128)\end{array}$ \\
\hline Graduated employees (\%) & & & $\begin{array}{c}-0.0778^{*} \\
(-0.158-0.00258)\end{array}$ & $\begin{array}{c}-0.0775^{*} \\
(-0.163-0.00806)\end{array}$ \\
\hline Young employees (\%) & & & $\begin{array}{c}0.0123 \\
(-0.0175-0.0422)\end{array}$ & $\begin{array}{c}0.0123 \\
(-0.0208-0.0455)\end{array}$ \\
\hline Employees training & & & $\begin{array}{c}-0.0160^{*} \\
(-0.0327-0.000595)\end{array}$ & $\begin{array}{c}-0.0163^{*} \\
(-0.0329-0.000266)\end{array}$ \\
\hline White collar (\%) & & & $\begin{array}{c}-0.00140 \\
(-0.0394-0.0366)\end{array}$ & $\begin{array}{c}-0.00165 \\
(-0.0402-0.0369)\end{array}$ \\
\hline Export (\% of revenues) & & & $\begin{array}{c}-0.0268^{*} \\
(-0.0552-0.00159)\end{array}$ & $\begin{array}{c}-0.0269^{*} \\
(-0.0565-0.00263)\end{array}$ \\
\hline Patents & & & $\begin{array}{c}0.00768 \\
(-0.0140-0.0294)\end{array}$ & $\begin{array}{c}0.00761 \\
(-0.0148-0.0300)\end{array}$ \\
\hline Vertical Dis-integration & & & $\begin{array}{c}-0.0736^{* *} \\
(-0.143--0.00459)\end{array}$ & $\begin{array}{c}-0.0738^{* *} \\
(-0.137--0.0105)\end{array}$ \\
\hline Sector dummies & Yes & Yes & Yes & Yes \\
\hline Year dummies & Yes & Yes & Yes & Yes \\
\hline Constant & $1.573^{* * *}$ & $1.572^{* * *}$ & $1.647 * * *$ & $1.647 * * *$ \\
\hline Sigma & $\begin{array}{c}(1.511-1.634) \\
0.284^{* * *} \\
(0.246-0.322)\end{array}$ & $\begin{array}{c}(1.512-1.632) \\
0.284^{* * *} \\
(0.245-0.323)\end{array}$ & $\begin{array}{c}(1.557-1.738) \\
0.283^{* * *} \\
(0.243-0.324)\end{array}$ & $\begin{array}{c}(1.563-1.731) \\
0.283^{* * *} \\
(0.246-0.321)\end{array}$ \\
\hline Observations & 10,398 & 10,398 & 10,398 & 10,398 \\
\hline Chi-square & 332.7 & 350 & 364.2 & 362.2 \\
\hline Log Lik & 2956 & 2956 & 2969 & 2970 \\
\hline
\end{tabular}

